Article

\title{
Evaluation of the Removal of Selected Phthalic Acid Esters (PAEs) in Municipal Wastewater Treatment Plants Supported by Constructed Wetlands
}

\author{
Daniel Wolecki $^{1, *(D)}$, Barbara Trella ${ }^{1}$, Fei Qi $^{2}$, Piotr Stepnowski ${ }^{1}$ and Jolanta Kumirska ${ }^{1, *(D)}$ \\ 1 Department of Environmental Analysis, Faculty of Chemistry, University of Gdansk, Wita Stwosza 63, \\ 80-308 Gdansk, Poland; basiatrella95@gmail.com (B.T.); piotr.stepnowski@ug.edu.pl (P.S.) \\ 2 Beijing Key Lab for Source Control Technology of Water Pollution, College of Environmental Science and \\ Engineering, Beijing Forestry University, Beijing 100083, China; qifei@bjfu.edu.cn \\ * Correspondence: daniel.wolecki@phdstud.ug.edu.pl (D.W.); jolanta.kumirska@ug.edu.pl (J.K.); \\ Tel.: +48-58-523-51-93 (D.W.); +48-58-523-50-14 (J.K.)
}

Citation: Wolecki, D.; Trella, B.; Qi, F.; Stepnowski, P.; Kumirska, J. Evaluation of the Removal of Selected Phthalic Acid Esters (PAEs) in Municipal Wastewater Treatment Plants Supported by Constructed Wetlands. Molecules 2021, 26, 6966. https://doi.org/10.3390/ molecules26226966

Academic Editors: Lidia Wolska, Marta Potrykus, Ewa Olkowska and Antonio Zuorro

Received: 30 September 2021 Accepted: 15 November 2021 Published: 18 November 2021

Publisher's Note: MDPI stays neutral with regard to jurisdictional claims in published maps and institutional affiliations.

Copyright: (c) 2021 by the authors. Licensee MDPI, Basel, Switzerland. This article is an open access article distributed under the terms and conditions of the Creative Commons Attribution (CC BY) license (https:// creativecommons.org/licenses/by/ $4.0 /)$.

\begin{abstract}
Phthalic acid esters (PAEs) have a negative impact on living organisms in the environment, therefore, are among the group of Endocrine Disrupting Compounds (ECDs). Unfortunately, conventional methods used in municipal wastewater treatment plants (MWWTPs) are not designed to eliminate PAEs. For this reason, the development of cheap and simple but very effective techniques for the removal of such residues from wastewater is crucial. The main aim of this study was the evaluation of the removal of six selected PAEs: diethyl phthalate (DEP), di-n-octyl phthalate (DOP), di- $n$-butyl phthalate (DBP), benzyl butyl phthalate (BBP), bis(2-ethylhexyl) phthalate (DEHP) and dimethyl phthalate (DMP), in real MWWTPs supported by constructed wetlands (MWWTP-CW system). For the first time, the possibility of using three new plants for this purpose, Cyperus papyrus (papyrus), Lysimachia nemorum (yellow pimpernel) and Euonymus europaeus (European spindle), has been presented. For determining the target PAEs in wastewater samples, a method of SPE (SolidPhase Extraction)-GC-MS(SIM) was developed and validated, and for plant materials, a method of UAE (Ultrasound-Assisted Extraction)-SPE-GC-MS(SIM) was proposed. The obtained data showed that the application of the MWWTP-CW system allows a significant increase in the removal of DEP, DBP, BBP and DEHP from the wastewater stream. Euonymus europaeus was the most effective among the tested plant species for the uptake of analytes ( $8938 \mathrm{ng} \times \mathrm{g}^{-1}$ dry weight), thus, this plant was found to be optimal for supporting conventional MWWTPs.
\end{abstract}

Keywords: phthalic acid esters; constructed wetlands; municipal wastewater; plant

\section{Introduction}

Phthalic acid esters (PAEs), usually called phthalate esters or just phthalates, were introduced into the industrial sector in the 1930s as plasticizers to give plastics their intended shape [1]. Since then, PAEs have been used in packaging materials, textiles, medical equipment and the production of electronics [2]. In some synthetics, such as polyvinyl chloride (PVC), phthalates account for $60 \%$ of the weight of the produced material [3]. By 2011, world production of plasticizers amounted to 8 million tons, and according to scientific reports, it is growing steadily [4]. Phthalic acid esters in living organisms can induce an effect like estrogens; therefore, PAEs are among the group of Endocrine Disrupting Compounds (ECDs). Data from in silico experiments have shown that some PAEs cause harmful effects on mammalian and non-mammalian organisms (e.g., [5]). For example, dibutyl phthalate (DBP) and benzyl butyl phthalate (BBP) and their metabolites were shown to be indicative of hemolysis and eryptosis in human erythrocytes [6]. For this reason, in many countries around the world, appropriate regulations have been introduced regarding the use and marketing of phthalate-containing products. For example, bis(2-ethylhexyl) phthalate 
(DEHP), dibutyl phthalate (DBP), benzyl butyl phthalate (BBP) and diisobutyl phthalate (DIBP) are included in Commission Regulation (EU) 2018/2005, amending Annex XVII to Regulation (EC) No 1907/2006 of the European Parliament and the Council concerning the Registration, Evaluation, Authorization and Restriction of Chemicals (REACH) [7]. However, the constant release of phthalates causes the accumulation of PAEs in different environmental niches [8]. For example, the presence of PAEs has already been confirmed in sediments and marine organisms of the Baltic Sea, which is a significant environmental threat [9].

Conventional methods used in wastewater treatment plants (WWTPs) for wastewater treatment are not designed to eliminate PAEs [10] and under typical conditions, only $18 \%$ of PAEs can be removed by WWTPs. For this reason, wastewater leaving WWTPs is one of the main sources of PAEs in the environment $[4,11,12]$. Since conventional activated sludge (AS)-based WWTPs are inefficient in the removal of PAEs, the implementation of additional wastewater cleaning processes is necessary. Thus, the development of efficient and cheap methods of wastewater treatment regarding the removal of PAEs is an important task for the protection of the environment and environmental engineering.

Constructed wetlands (CWs) are a green chemistry approach, where plants capable of growing in highly hydrated conditions are used to remove contaminants $[13,14]$. CWs are systems in which water, soil, plants and microorganisms interact to greatly benefit the elimination of pollutants. In most cases, CWs in WWTPs are a separate sector of the wastewater treatment process, implemented after biological treatment. They include the following configurations: surface flow constructed wetlands (SFCWs), horizontal surface flow constructed wetlands (HSSFCWs) and vertical subsurface flow constructed wetlands (VSSFCWs) [10] (Figure 1).
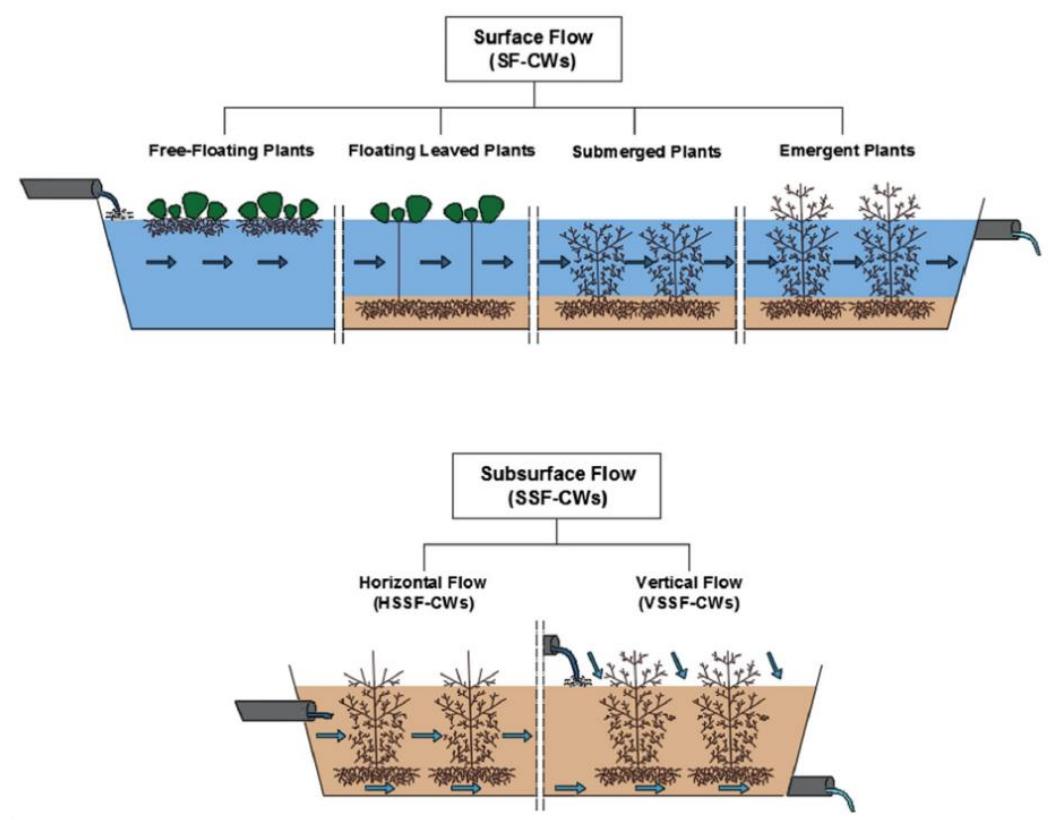

Figure 1. CWs configurations, according to hydrology (surface or subsurface flow), plant growth forms for surface flow (free-floating, floating leaved, submerged or emergent) and flow path for subsurface flow (horizontal or vertical). Reprinted from Environmental Pollution, Vol 227, Ana M. Gorito, Ana R. Ribeiro, C.M.R. Almeida, Adrian M.T. Silva, A review on the application of constructed wetlands for the removal of priority substances and contaminants of emerging concern listed in recently launched EU legislation, Pages No. 428-443, Copyright (2017) [10], with permission from Elsevier. (License Number 5166980675287). 
CWs could be also implemented within the second stage of wastewater treatment (biological). Contact between the plants and wastewater (mixed with AS) can occur only in the rhyzophytic zone.

In comparison to classic pollutants (such as biogens or organic substances), CWs are the perfect complement to wastewater treatment technology [15]. The removal mechanism of contaminants in CWs is complicated and consists of physical, chemical and biological processes among the plants, substrates and microorganisms. It can also be affected by the type of CW, the substrate type and the plants used [10]. The literature data [16-28] describing the use of CWs in WWTPs for the effective neutralization/sorption/degradation of phthalates are very limited (Table S1, Supplementary Material). Most investigations are performed using a laboratory system [16-21] or a pilot-scale system [22-25,28]. A full-scale constructed wetland experiment is only presented in a few papers [26,27]. Moreover, the uptake of PAEs by plants in CWs is seldom investigated. Such data are only presented for a laboratory system and such plants as Phragmites australis by Li et al. [16], and Brassica juncea and Helianthus annuus by Zavoda et al. [21]. The uptake of PAEs by Typha plants in working full-scale CW systems was investigated only recently by Diepenheim et al. [27]. One of the main reasons for the sparse research is the limited number of analytical methods developed for the determination of PAEs in plant materials. The literature data available on this topic [2,29-33] are presented in Table S2, and in most cases, the papers describe the phytoremediation of PAEs by vegetables planted in contaminated soils.

Taking into account the information presented above, the main aim of this study was to evaluate the removal of PAEs in a working municipal wastewater treatment plant (MWWTP) supported by CWs by the simultaneous determination of PAEs in raw and treated sewage, in addition to the determination of the uptake of the target compounds by plants in CWs. Contrary to the working full-scale CW system investigated by Diepenheim et al. [27], where an operational horizontal subsurface flow CW received effluent from an adjacent WWTP, in this study CWs were introduced in the stage of biological wastewater treatment. Moreover, for the first time, the possibility of using three new plants for this purpose: Cyperus papyrus (papyrus), Lysimachia nemorum (yellow pimpernel) and Euonymus europaeus (European spindle), has been presented. However, because appropriate analytical methods for the simultaneous determination of the six target phthalates (Table S3, Supplementary Material) in wastewater and CW plants were not available, the main objectives of this work were as follows: (1) the modification of an analytical method for the determination of PAEs in raw and treated sewage water; (2) the modification of an analytical method for the determination of selected PAEs in plant materials from CWs; (3) the determination of selected phthalates in raw and treated sewage samples from an MWWTP supported by CWs; (4) an assessment of the uptake of PAEs by plants used in CWs; (5) an evaluation of the possibility of using hydroponic cultivations for the effective removal of PAEs in MWWTPs.

According to information included in the literature [2,29-33], the most frequently used technique for the isolation of PAEs from plant materials is Ultrasound-Assisted Extraction (UAE) [2,27,31-33] (Tables S1 and S2). In this study, we decided to verify the usefulness of this technique for the isolation of the target compounds from the plants: Cyperus papyrus (papyrus), Lysimachia nemorum (yellow pimpernel) and Euonymus europaeus (European spindle). Such investigations were not performed in any of the published papers.

\section{Results and Discussion}

\subsection{Evaluation of the Analytical Method for Determining the Target Compounds in} Sewage Samples

Three different SPE cartridges, Oasis HLB, Strata C18-ec and Strata X, were tested in order to find the optimal conditions for the extraction of the target compounds from wastewater samples (Section 3.4). The absolute recoveries (\%) of the target PAEs extracted from distilled water spiked with phthalates to a concentration of each analyte of $4 \mu \mathrm{g} \times \mathrm{L}^{-1}$ and acidification to $\mathrm{pH} 3$ are shown in Figure 2. All obtained extracts were analyzed using the GC-MS(SIM) method presented in Section 3.6. 


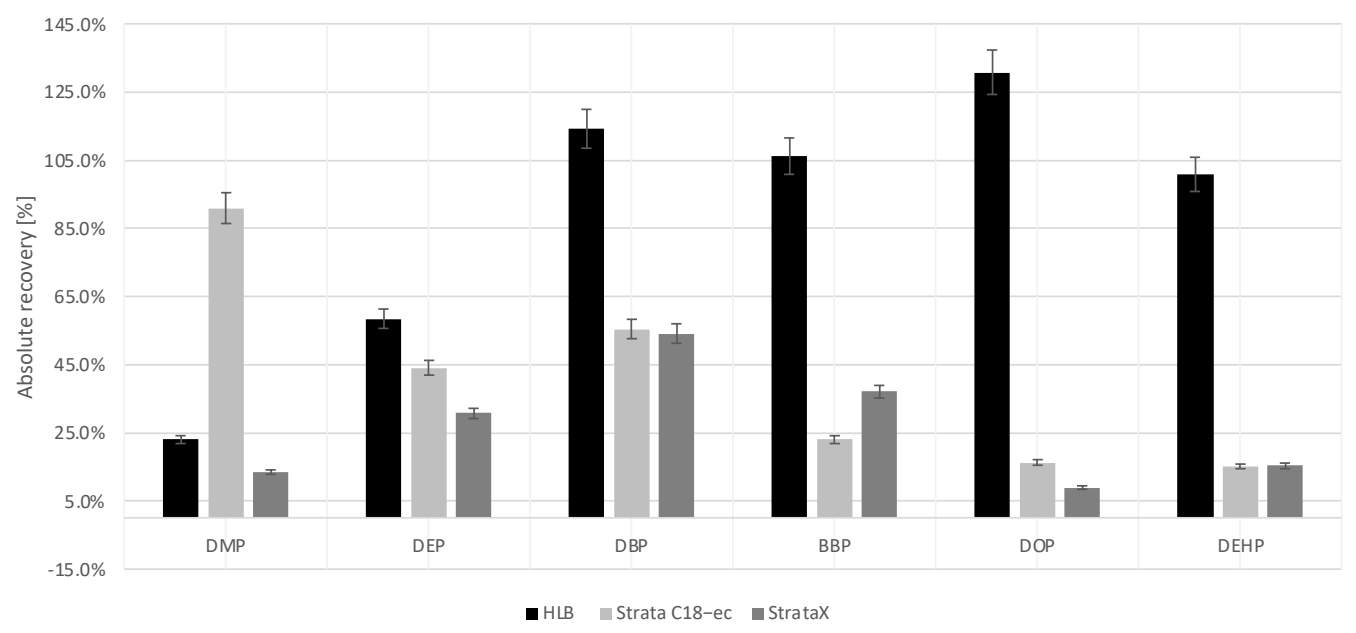

Figure 2. Absolute recovery ( $\mathrm{AR} \pm \mathrm{SD}, \%$ ) of six target PAEs using different types of SPE cartridges (Oasis HLB, Strata C18-ec and Strata X; $n=3$ ).

Among the tested SPE cartridges, the most effective was the hydrophilic-lipophilic balance water-wettable sorbent, namely, Oasis HLB (Figure 2). The AR values of DBP, BBP, DOP and DEHP were $114 \% \pm 1 \%, 106 \% \pm 6 \%, 131 \% \pm 6 \%$ and $101 \% \pm 6 \%$, respectively. For more polar phthalates such as DMP and DEP, the AR values were lower (Figure 2). Measurement precision, expressed by the standard deviation (SD), was satisfactory and did not exceed $6 \%$. Surprisingly, the application of the Strata X cartridge with a solid-phase structure similar to Oasis HLB was not satisfactory enough for the extraction of PAEs. On the other hand, the SD values in this case were the lowest among all those recorded for the tested cartridges. Summarizing, the Oasis HLB cartridge with the extraction sequence described in Section 3.4 was chosen as optimal for the extraction of the target PAEs from water samples.

In order to fully optimize the analytical method, raw and treated sewage samples containing trace levels of PAEs were spiked with a known amount of the target phthalates (250 $\mathrm{ng} \times \mathrm{L}^{-1}, 500 \mathrm{ng} \times \mathrm{L}^{-1}$ and $1000 \mathrm{ng} \times \mathrm{L}^{-1}$ ) and subjected to extraction. The analysis of non-spiked wastewater samples was also performed. In both matrix types, untreated and treated sewage samples, the absolute recovery data were evaluated; the results are presented in Table 1.

Table 1. Absolute recovery (mean $\pm \mathrm{SD}, \%$ ) of the target PAEs from wastewater samples spiked with the target phthalates to the concentrations: $250 \mathrm{ng} \times \mathrm{L}^{-1}, 500 \mathrm{ng} \times \mathrm{L}^{-1}$ and $1000 \mathrm{ng} \times \mathrm{L}^{-1}$, using Oasis HLB ( $\mathrm{n}=3)$.

\begin{tabular}{ccc}
\hline \multirow{2}{*}{ Phthalates } & Raw Sewage & Treated Sewage \\
\cline { 2 - 3 } & \multicolumn{2}{c}{ Mean \pm SD (\%) } \\
\hline DMP & $126 \pm 5$ & $118 \pm 6$ \\
\hline DEP & $109 \pm 17$ & $121 \pm 6$ \\
\hline DBP & $120 \pm 25$ & $113 \pm 11$ \\
\hline BBP & $189 \pm 25$ & $137 \pm 9$ \\
\hline DOP & $115 \pm 13$ & $39 \pm 2$ \\
\hline DEHP & $108 \pm 14$ & $36 \pm 2$ \\
\hline
\end{tabular}


The literature data concerning studies of the usefulness of hydroponically cultivated plants for removing PAEs from the sewage stream do not present the absolute recoveries of analytes in the development of the applied analytical methods, yet sometimes recoveries calculated based on surrogate solutions are presented. (Table S1, Supplementary Material). Some show only the concentrations of PAEs in the sewage/water samples without details describing the applied analytical protocols, and sometimes only the theoretical concentration in the water phase was considered in such studies [2]. The recoveries of DMP, DEP, DBP, BBP and DOP from water samples using Oasis HLB cartridges during SPE-GC-FID analyses reported by Xiaoyan et al. (2015) ranged from $74 \%$ to $108 \%$ [20]. Reyes-Contreras and co-workers (2011) used a previously developed method for determining pharmaceuticals in CWs in order to determine phthalates in wastewaters and established that the recoveries of all analytes were always above 90\% [22]. Similar results were obtained by Masi et al. (2004), who applied a liquid/liquid extraction procedure with GC-MS measurements; the established recoveries ranged from $60 \%$ to $97 \%$ [24]. According to Zhao et al. (2004), the recovery of DBP from water samples based on a $C_{18}$ SPE procedure coupled with HPLC was 141.2\% [25]. Diepenheim et al. [27] developed an SPE-GC-MS method for the simultaneous determination of 15 PAEs in wastewater, including the phthalates investigated in this study. They used $47 \mathrm{~mm}$ HLB Oasis disks for their extraction. PAEs were eluted using $2 \times 3 \mathrm{~mL}$ of hexanes and $3 \mathrm{~mL}$ of ethyl acetate. Next, the samples were concentrated, exchanged to hexanes and spiked with the internal standard [27]. The average recoveries for the laboratory control samples (500 to $1500 \mathrm{ng}$ of phthalates) were $79 \% \pm 38 \%$. The matrix spike average recoveries were $100 \%$ (a range from $32 \%$ to $137 \%$ ) for water [27].

Jiang and co-workers (2018) [34] developed an SPE-LC-MS/MS method for the simultaneous determination of primary and secondary phthalate monoesters, which was applied to determine these compounds in the Taihu Lake surface water. Unfortunately, only the recoveries for primary monoesters of phthalic acid were presented (a range from 76.8 to $86.2 \%$ ) [34]. Ballesteros and co-workers (2006) [35] determined phthalate esters, alkylphenols, bisphenol $\mathrm{A}$ and their chlorinated derivatives in wastewater samples using an SPE-GC-MS method. The recoveries of PAEs based on a surrogate solution (bisphenol F) (DMP 96.0-105.0\%, DEP 95.6-98.0\%, DBP 96.0-103.4\%) [35] were similar to those presented in Table 1. However, because the recoveries were calculated based on the surrogate solution, a direct comparison with the absolute recoveries presented in this paper is not possible. Adewuyi (2012) determined DMP, DEP, DPhP, DBP and DEHP in sewage and water samples using liquid-liquid extraction (dichloromethane as the extraction medium), the purification of the extracts on a column of silica gel with hexane as the mobile solvent and an analysis of the cleaned extracts by HPLC [36]. The recoveries of analytes, calculated based on an internal standard (IS), ranged from 57.48\% (DPhP) to 96.95\% (DEHP) [36]. In summary, it can be concluded that the recoveries of analytes presented in this study were similar to those in the literature [20,22,24,25,34-36]. However, in this study, such data are shown as absolute recoveries, whereas in the cited literature they are shown mostly as relative recoveries without the presentation of absolute recoveries.

\subsection{Evaluation of the Analytical Method for Determining the Target Compounds in Plant Materials}

Knowledge of the impact of the plant species in CWs on the removal of phthalates from wastewater requires an assessment of the uptake of these compounds by plants. Based on the literature data (Table S1, Supplementary Material), the required methodology was evaluated and the concentrations of compounds in CW plant materials were established: DBP for Phragmites australis [16], DBP, DOP and BBP for Brassica juncea and Helianthus annuus plants [21] as well as for Typha (15 PAEs) [27]. Moreover, such studies were conducted mainly for laboratory systems, and only in one case for a working full-scale MWWTP-CW system [27] (details in Table S1 in Supplementary Material). Thus, the development of an analytical procedure for determining the six target PAEs in the plants selected in this study was necessary. For this reason, after the development of the GC-MS(SIM) method de- 
scribed in Section 3.6 for the final determination and evaluation of the extraction efficiency of the target compounds from sewage samples, our research focused on the optimization of the extraction of phthalates from plant materials. As mentioned in the Introduction, based on the Supplementary Material (Tables S1 and S2), the most frequently used technique for the isolation of PAEs from plant materials is UAE [2,27,31-33]. We decided to optimize the UAE conditions (the application of different extraction solvents, ethyl acetate (EtOAc), methanol $(\mathrm{MeOH})$ and dichloromethane (DCM)), and to use the previously proposed SPE procedure for the purification of the obtained extracts.

The results of the optimization of the UAE procedure are presented in Table 2 . The best absolute recoveries of the target PAEs (ranging from $32 \pm 4 \%$ (DMP) to $130 \pm 31 \%$ (DOP)) with the lowest standard deviation (SD) were obtained during the application of $\mathrm{DCM}$ as the extraction solvent. With the use of $\mathrm{MEOH}$, lower AR values were observed for all PAEs, and for DEHP this value was unsatisfactory (14 $\pm 3 \%$ ) (Table 2) (acceptable criteria for AR $>30 \%$ [37]). During the application of EtOH as the extraction medium, better absolute recovery results were observed for DEP (60 $\pm 16 \%$ instead of $43 \pm 8 \%$ ) and DBP (102 $\pm 31 \%$ instead of $83 \pm 6 \%$ ); however, the SD values were much higher than those observed for extraction using DCM. Moreover, DOP was not isolated in these conditions.

Table 2. Absolute recoveries (mean $\pm \mathrm{SD}$ ) of six analytes using different solvents during the UAE procedure $\left(\mathrm{n}=3\right.$, conc. $1000 \mathrm{ng} \times \mathrm{g}^{-1}$ d.w. $)$.

\begin{tabular}{|c|c|c|c|}
\hline \multirow{2}{*}{$\begin{array}{c}\text { Type of } \\
\text { Solvents/Phthalates }\end{array}$} & $\mathrm{MeOH}$ & EtOAc & DCM \\
\hline & \multicolumn{3}{|c|}{ Value of Absolute Recovery $[\% \pm$ SD (\%)] } \\
\hline DMP & $29 \pm 8$ & $29 \pm 16$ & $32 \pm 4$ \\
\hline DEP & $39 \pm 10$ & $60 \pm 16$ & $43 \pm 8$ \\
\hline DBP & $62 \pm 7$ & $102 \pm 31$ & $83 \pm 6$ \\
\hline BBP & $61 \pm 6$ & $80 \pm 21$ & $80 \pm 4$ \\
\hline DOP & $120 \pm 23$ & $<\mathrm{MDL}$ & $130 \pm 31$ \\
\hline DEHP & $14 \pm 3$ & $69 \pm 26$ & $68 \pm 3$ \\
\hline
\end{tabular}

In order to compare the recovery data obtained in this work with those presented by other research groups for PAEs extracted from plant materials, we collected the literature data assessing the uptake of these compounds by plants, respectively in Tables S1 and S2. Unfortunately, only four papers [16,27,29,33] presented recovery data. Li et al. [16] reported that the recovery of DBP from Phragmites australis based on a UAE-GC-MS method was $89 \%$. Diepenheim et al. [27] established that the matrix spike average recoveries of analytes for plant samples were $72 \%$ (a range from $0 \%$ to $121 \%$ ). Liao et al. [29] confirmed that the recovery percentage of DBP isolated from garden lettuce (Lactuca sativa L. var. longifolia) was $96.5 \%$. Sun et al. [33] proved that the recoveries of DBP and DEHP from lettuce Lactuca sativa, strawberry Fragaria $\times$ ananassa and carrot Daucus carota Var. Sativa, calculated based on internal standards, ranged from 75 to $110 \%$. Sablayrolles et al. (2005) developed and validated a method of extracting phthalates from sludge and vegetables [38]. The authors determined the same phthalates as in our study but the isolation of PAEs from plant materials was performed using the Soxhlet extraction method with $n$-hexane as the extraction matrix and the purification of the obtained extracts by SPE (Florisil). Relative recoveries (internal standard; $\mathrm{DEHP}-\mathrm{d}_{4}$ ) ranged from 100 to 101\% [38]. Holadová and Hajšlová (1995) [39] described the development of a method for determining the same phthalates as in our study, using homogenization with a hexane/acetone $(2: 1, v / v)$ mixture and GC-ECD. Based on deuterated standards (DEHP- $\mathrm{d}_{4}$ and DBP- $\mathrm{d}_{4}$ ), the relative recoveries of PAEs from lettuce samples ranged from 50 to $120 \%$. Generally, our research presents absolute recovery data, not relative recoveries, so a direct comparison of the obtained results with those presented in other studies is problematic. Taking into account that the 
criterion acceptable for AR is above 30\% [37], the proposed UAE-SPE procedure fully fulfills this requirement.

As mentioned, the chromatographic conditions of the GC-MS measurements of plant extracts are presented in Section 3.6.

\subsection{Validation Parameters of the Proposed SPE-G-MS(SIM) and UAE-SPE-GC-MS(SIM) Methods for Determining Phthalates in Wastewater and Plants}

The developed methods for determining target PAEs in wastewater and plants were validated using working calibration standard solutions and matrix-matched calibration solutions according to the guidelines of the International Vocabulary of Metrology [40] and procedures fully described in our previous papers [41,42] (Section 3.7). The determined validation parameters are presented in Table 3. The coefficient of determination $\left(\mathrm{R}^{2}\right)$ ranged from 0.9941 to 0.9986 and the intermediate precision measurement from 0.2 to $9.2 \%$. Accuracy, expressed by the mean recovery (MR), based on the determined and known concentrations of analytes, was between $80 \%$ and $114 \%$ for plants and between $80 \%$ and $120 \%$, and $80 \%$ and $119 \%$ for raw and treated wastewater, respectively (Table 3 ). Matrix effects (ME) for plants ranged from $-24 \pm 4 \%$ for DMP to $3 \pm 1 \%$ for DEHP. For wastewater samples, ME values were between $-25 \pm 6 \%$ and $+50 \pm 14 \%$ for untreated wastewater, and between $-35 \pm 7 \%$ and $+34 \pm 9 \%$ for treated wastewater (Table 3). A comparison of the obtained ME values with those presented by other authors was not possible because matrix effects were not presented in the cited papers (Tables S1 and S2). Fernández-González et al. (2017) determined the matrix effects for the HS-SPME-GC-MS determination of phthalates in sediment samples [43]. They proved that the ones for DMP, DEP, DBP, and BBP were negligible. However, ME values for DEHP and DOP were $40 \%$ and $60 \%$, respectively. In our opinion, the matrix effects determined in this study, which did not exceed $50 \%$, in combination with other validation parameters (Table 3 ) and $\mathrm{ME}$ data presented for environmental matrices [37,43], are satisfactory.

The method quantification limit and method detection limit values were almost the same or similar to those presented in other research [2,16-33].

\subsection{Determination of Selected Phthalates in Wastewater and Plant Materials from an MWWTP}

\subsubsection{Assessment of the Presence of Phthalates in Raw and Treated Wastewater}

The method for determining target PAEs in raw and treated wastewater was described in Section 2.1 and 3.4. The identification of analytes was performed based on the retention time, quantitative ion and confirmation ions, described in Section 3.6. The mass spectra of the target compounds with the assignation of MS fragments are included in Figure S2 in Supplementary Material. The determined concentrations of the six target compounds in untreated and treated sewage collected from the studied full-scale MWWTP supported by CWs, characterized in Section 3.2, are presented in Table 4. 


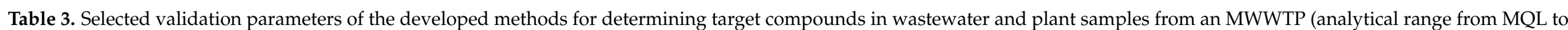

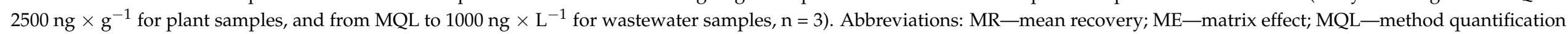
limit; MDL—method detection limit; UW—untreated wastewater; TW—-treated wastewater.

\begin{tabular}{|c|c|c|c|c|c|c|c|c|c|c|c|c|}
\hline \multirow{2}{*}{$\begin{array}{l}\begin{array}{l}\text { Validation } \\
\text { Parameters }\end{array} \\
\text { Compounds } \\
\end{array}$} & \multirow{2}{*}{ Calibration Curves } & \multirow{2}{*}{$\mathbf{R}^{2}$} & \multirow{2}{*}{$\begin{array}{l}\text { Intermediate Precision } \\
\text { Measurement (RSD) \% }\end{array}$} & \multicolumn{3}{|c|}{$\begin{array}{l}\text { MR } \\
{[\%]}\end{array}$} & \multicolumn{3}{|c|}{$\begin{array}{c}\text { ME } \\
{[\% \pm \mathrm{SD}]}\end{array}$} & \multicolumn{3}{|c|}{$\begin{array}{c}\text { MQL; MDL } \\
{\left[n g \times \mathbf{L}^{-1} \text { or ng } \times \mathbf{g}^{-1} \text { d.w.] }\right.}\end{array}$} \\
\hline & & & & UW & TW & Plants & UW & TW & Plants & UW & TW & Plants \\
\hline DMP & $17988.73 X+683.92$ & 0.9960 & $2.0-5.8$ & $80-111$ & $84-119$ & $83-111$ & $+17 \pm 9$ & $+34 \pm 9$ & $-24 \pm 4$ & $5 ; 2$ & $6 ; 2$ & $30 ; 10$ \\
\hline DEP & $45676.99 X+1352.61$ & 0.9965 & $1.3-5.9$ & $90-120$ & $80-118$ & $80-112$ & $+45 \pm 11$ & $+8 \pm 2$ & $-17 \pm 3$ & $6 ; 2$ & $7 ; 2$ & $23 ; 8$ \\
\hline DBP & 117497.40X + 348.26 & 0.9956 & $2.3-9.2$ & $85-114$ & 90-111 & $90-113$ & $-25 \pm 6$ & $-13 \pm 4$ & $-10 \pm 1$ & $5 ; 2$ & $6 ; 2$ & $12 ; 4$ \\
\hline BBP & $51801.06 X-711.14$ & 0.9960 & $0.2-8.0$ & $90-118$ & 95-105 & $90-114$ & $+40 \pm 17$ & $+14 \pm 4$ & $-6 \pm 1$ & $3 ; 1$ & $4 ; 1$ & $12 ; 4$ \\
\hline DOP & 110988.50X - 1483.44 & 0.9986 & $0.8-8.1$ & 95-106 & $90-108$ & 94-108 & $+50 \pm 14$ & $-35 \pm 7$ & $-10 \pm 2$ & $5 ; 2$ & $7 ; 2$ & $8 ; 3$ \\
\hline DEHP & 144296.80X - 6362.41 & 0.9941 & $1.8-5.9$ & $80-104$ & $85-115$ & $90-103$ & $+29 \pm 8$ & $-30 \pm 5$ & $3 \pm 1$ & $6 ; 2$ & $4 ; 1$ & $14 ; 5$ \\
\hline
\end{tabular}


Table 4. Concentrations of target compounds in raw and treated sewage samples collected from the studied full-scale MWWTP supported by CWs, determined using the developed SPE-GC-MS(SIM) method $(n=3)$.

\begin{tabular}{|c|c|c|}
\hline \multirow{2}{*}{ Phthalates } & Concentration in Raw Sewage & Concentration in Treated Sewage \\
\hline & \multicolumn{2}{|c|}{$($ mean $\pm \mathrm{SD})\left[\mathrm{ng} \times \mathrm{L}^{-1}\right]$} \\
\hline DMP & $<\mathrm{MDL}$ & $<\mathrm{MDL}$ \\
\hline DEP & $10,097 \pm 202$ & $178 \pm 0$ \\
\hline DBP & $6196 \pm 805$ & $397 \pm 8$ \\
\hline BBP & $204 \pm 2$ & $89 \pm 0$ \\
\hline DOP & $221 \pm 7$ & $264 \pm 3$ \\
\hline DEHP & $136 \pm 0$ & $41 \pm 0$ \\
\hline
\end{tabular}

In this study, for the first time in Poland and this part of Europe, the concentrations of phthalates, which pose a danger to living organisms, in sewage derived from a fullscale MWWTP supported by CWs were investigated. In both raw and treated sewage samples, DMP was not found (concentration below the method detection limit (MDL)). Two phthalates, DEP and DBP, were found in the highest concentrations in raw sewage at $10,097 \pm 202 \mathrm{ng} \times \mathrm{L}^{-1}$ and $6196 \pm 805 \mathrm{ng} \times \mathrm{L}^{-1}$, respectively (Table 5). BBP, DOP and DEHP were determined at the concentrations $204 \pm 2 \mathrm{ng} \times \mathrm{L}^{-1}, 221 \pm 7 \mathrm{ng} \times \mathrm{L}^{-1}$ and $136 \pm 0 \mathrm{ng} \times \mathrm{L}^{-1}$, respectively, in raw sewage. The concentrations of DEP and DBP, as well as BBP and DEHP, were lower in treated sewage in comparison to raw sewage, with the biggest differences observed for DEP and DBP (Table 4). Only the concentration of DOP in treated sewage was $20 \%$ higher than in raw sewage. The probable reason for this result could be the additional pollution of the wastewater by active and passive elements of the WWTP, made of plastic. In order to prove this result, a repetition analysis was performed, and again a higher DOP concentration in treated wastewater was observed. Moreover, we have performed an analysis of wastewater samples using a full scan GC-MS system with the registration of the total ion chromatogram (TIC). No co-elution or signal overlap was observed. The exemplary TICs recorded for raw (A) and treated (B) wastewater samples are presented in Supplementary Materials in Figure S3. A similar situation was observed by Gao et al. (2014) who determined the concentrations of phthalates in untreated and treated sewage, and also determined a higher concentration of DOP in treated sewage (mean concentration $9.22 \mathrm{ng} \times \mathrm{mL}^{-1}$ ) than in untreated (mean concentration $8.08 \mathrm{ng} \times \mathrm{mL}^{-1}$ ) [44]. The mean concentration of BBP in the effluent $\left(8.3 \mathrm{ng} \times \mathrm{mL}^{-1}\right)$ was also higher than this one in the influent $\left(3.66 \mathrm{ng} \times \mathrm{mL}^{-1}\right)$ [44].

Our results confirmed the presence of target PAEs in raw and treated sewage from WWTPs (Table 4). Similar data are presented in other research (Table S1). To the best of our knowledge, only two studies [26,27] reported the determination of phthalates in full-scale CWs (Table S1). CWs were found to have a negative effect on PAE concentrations in sewage in both summer and winter [26], whereas positive results were reported by Diepenheim et al. [27]. Some studies [22-25,28] describe pilot-scale CWs or those existing as stand-alone hydroponic crops [17-21] (Table S1).

Gani and Kazmi (2016) determined DEP, DBP, BBP and DEHP in sewage and their removal in a sequencing batch reactor (SBR), activated sludge process (ASP) and upflow anaerobic sludge blanket (UASB) reactor [45]. They reported the concentrations of these compounds in raw wastewater at $5417 \pm 4149 \mathrm{ng} \times \mathrm{L}^{-1}, 11,175 \pm 9977 \mathrm{ng} \times \mathrm{L}^{-1}$, $1968 \pm 2280 \mathrm{ng} \times \mathrm{L}^{-1}$ and $27,011 \pm 14,341 \mathrm{ng} \times \mathrm{L}^{-1}$, respectively [45]. In treated wastewater, DBP and DEHP concentrations were much higher than those reported in our research, $2188 \pm 1847 \mathrm{ng} \times \mathrm{L}^{-1}$ and $4253 \pm 2521 \mathrm{ng} \times \mathrm{L}^{-1}$, respectively. 
Table 5. Results of the determined target compounds in three species of hydroponically cultivated plants from an MWWTP using the developed UAE-SPE-GC-MS(SIM) method ( $\mathrm{n}=3)$, and the elimination efficiency of these compounds from wastewater in an MWWTP supported by CWs.

\begin{tabular}{ccccc}
\hline \multirow{2}{*}{ Phthalates } & $\begin{array}{c}\text { Cyperus papirus } \\
\text { (Papyrus) }\end{array}$ & $\begin{array}{c}\text { Lysimachia nemorum } \\
\text { (Yellow Pimpernel) }\end{array}$ & $\begin{array}{c}\text { Euonymus europaeus } \\
\text { (European Spindle) }\end{array}$ & EE \\
\cline { 2 - 5 } & \multicolumn{2}{c}{ (Mean \pm SD) $\left[\mathbf{n g} \times \mathbf{g}^{-\mathbf{1}}\right.$ Dry Weight] } & $\%$ \\
\hline DMP & $<\mathrm{MDL}$ & $98 \pm 2$ & $397 \pm 12$ & -1 \\
\hline DEP & $400 \pm 24$ & $313 \pm 38$ & $477 \pm 83$ & 98 \\
\hline DBP & $1596 \pm 215$ & $1697 \pm 140$ & $1284 \pm 278$ & 94 \\
\hline BBP & $1913 \pm 146$ & $<\mathrm{MDL}$ & $218 \pm 19$ & 56 \\
\hline DOP & $1828 \pm 196$ & $1343 \pm 193$ & $6562 \pm 1065$ & $0^{2}$ \\
\hline DEHP & $<\mathrm{MDL}$ & $53 \pm 22$ & $<\mathrm{MDL}$ & 70 \\
\hline
\end{tabular}

${ }_{1}$ if phthalate concentrations were below the MDL value in both raw and treated wastewater, the elimination efficiency (EE) was not calculated. ${ }^{2}$ for DOP, the concentration in treated wastewater was higher than in raw. Based on this, it was assumed that the elimination efficiency was $0 \%$ and another source of DOP contamination exists in the WWTP.

\subsubsection{Assessment of the Uptake of Phthalates in Hydroponically Cultivated Plants}

The determined concentrations of phthalates in three species of hydroponically cultivated plants (in $\mathrm{ng} \times \mathrm{g}^{-1}$ dry weight) and the elimination efficiency (EE) of phthalates calculated by Equation 2, described in Section 3.9, are presented in Table 5. Example chromatograms with marked SIM ions for the determined target compounds in real papyrus (Cyperus papyrus), yellow pimpernel (Lysimachia nemorum) and European spindle (Euonymus europaeus) samples are included in Figures S4-S6, respectively.

Among the six determined phthalic acid esters, three of them (DEP, DBP and DOP) were found in all the tested plant species (Cyperus papyrus, Lysimachia nemorum, Euonymus europaeus). Additionally, in E. europaeus, DOP was determined at the highest concentration of $6562 \pm 1065 \mathrm{ng} \times \mathrm{g}^{-1} \mathrm{~d}$.w., as well as DEP and DMP, at $477 \pm 83 \mathrm{ng} \times \mathrm{g}^{-1} \mathrm{~d}$.w. and $397 \pm 12 \mathrm{ng} \times \mathrm{g}^{-1}$ d.w., respectively (Table 5). C. papyrus plant material contained DEP, DBP, BBP and DOP, whereas DMP and DEHP were not found. In Lysimachia nemorum only BBP was not identified. DMP was determined at a concentration of $98 \pm 2 \mathrm{ng} \times \mathrm{g}^{-1} \mathrm{~d}$.w., DBP at a concentration of $1697 \pm 140 \mathrm{ng} \times \mathrm{g}^{-1}$ d.w., DOP at $1343 \pm 193 \mathrm{ng} \times \mathrm{g}^{-1} \mathrm{~d}$.w. and DEHP at $53 \pm 22 \mathrm{ng} \times \mathrm{g}^{-1} \mathrm{~d} . \mathrm{w}$. (Table 5).

Few studies $[16,21,27]$ have directly summarized the uptake of phthalates by plants in CWs (Table S1). Li et al. (2020) investigated the possibility of the uptake of DBP by the Phragmites australis plant in laboratory CWs [16]. The target compound was detected in plant tissue in variable concentrations during spring, summer and autumn, with the highest concentration (0.468-4.000 $\mu \mathrm{g} / \mathrm{g} \mathrm{d}$.w.) detected in autumn. Moreover, the authors concluded that DBP was preliminarily removed by biodegradation in this system and the uptake and substrate adsorption of $P$. australis were negligible for the removal of DBP [16]. Zavoda et al. [21] investigated the ability of dwarf sunflowers (Helianthus annuus) and two strains of mustard seed (Brassica juncea) to hydroponically treat water contaminated with the phthalates DBP, DOP and BBP. For individual phthalate treatment, the selectivity was DBP > BBP > DOP. The sunflowers had a better uptake rate and a higher concentration of contaminants in plant tissue than the mustard seed (over $100 \mathrm{ppm}$ of phthalates during a 4-day study). Diepenheim et al. [27] studied the distribution of 15 phthalates in water, sediment and two dominant plant species (Typha latifolia, Typha angustifolia) in a fully operational CW (Table S1). In contrast to our study, an operational horizontal subsurface flow CW received effluent from an adjacent WWTP. Plant species were sampled by collecting the portions emerging above the surface of the water. The average dry weight of $\Sigma 15$ phthalates was $1.23 \pm 0.53 \mu \mathrm{g} \times \mathrm{g}^{-1}$ for Typha shoots; DBP and DEHP were most often found. Significant concentrations of DBP, DEHP and other water-soluble phthalates in the shoots of Typha (for comparison: $0.088-2.02 \mu \mathrm{g} \times \mathrm{g}^{-1} \mathrm{~d}$.w. 
for DBP) indicated that plant uptake is a potentially important removal mechanism of phthalates in water exiting the CW [27].

In this study, the obtained elimination efficiency (EE) of the investigated phthalates from wastewater ranged from $56 \%$ for BBP to $98 \%$ for DEP (Table 5). In comparison, the literature EE data for DBP, presented in Table S1, are as follows: $>89.7 \%$ [16], 62.08-84.17\% [17], $87.2 \%$ [19], 99.99\% [23] and 99.84\% [25]. In our study, the elimination efficiency of DBP from wastewater was $94 \%$, which confirms a similar or higher elimination efficiency than presented by other studies. Lower EE values for DEP than the value determined in this study (98\%) were presented in [18] (48.2-61.5\%: Exp. I $144 \mu \mathrm{g} / \mathrm{L}$ in sewage; 55.8-67.5: Exp. II $150 \mu \mathrm{g} / \mathrm{L}$ in sewage), in [20] (44-83\%) and in [22] (in winter 73\%) (Table S1). Summarizing, the obtained results proved that the uptake of PAEs by plants in an MWWTP supported by CWs resulted in an increase in the effectiveness of the removal of such compounds from wastewater.

2.4.3. Assessment of the Usefulness of Hydroponically Cultivated Plants for Removing Phthalates from the Sewage Stream

In accordance with the literature data, the most frequently hydroponically cultivated plants are Typha sp., Phragmites sp. and T. aestivum (Table S1) due to the considerable size of the rhizomes and roots. In this study, the three plants, Cyperus papyrus (papyrus), Lysimachia nemorum (yellow pimpernel) and Euonymus europaeus (European spindle), were evaluated for the first time for this purpose. The above-mentioned plants are dominant since they adapt very well to growth in MWWTPs and show the strongest development during the growing season. To assess the usefulness of these species for removing phthalates from the wastewater stream, the sum of the uptake masses of phthalates taken by the tested species was calculated, and the results are presented in Table 6 .

Table 6. The sum of the uptake of selected phthalates in $\mathrm{ng} \times \mathrm{g}^{-1}$ dry weight by tested plant species growing in an MWWTP.

\begin{tabular}{cccc}
\hline Plant Species & Cyperus papyrus & Lysimachia nemorum & Euonymus europaeus \\
\hline \multirow{2}{*}{$\sum_{\text {selected PAEs }}$} & \multicolumn{3}{c}{$\left[\mathrm{ng}^{-1} \mathrm{dry}\right.$ weight $]$} \\
\cline { 2 - 4 } & 5737 & 3504 & 8938 \\
\hline
\end{tabular}

Accordingly, the highest uptake of target compounds was observed for Euonymus europaeus (European spindle) ( $8938 \mathrm{ng} \times \mathrm{g}^{-1}$ d.w.), followed by Cyperus papyrus (papyrus) (5737 ng $\times \mathrm{g}^{-1}$ d.w.), and the lowest uptake for Lysimachia nemorum (yellow pimpernel) (3504 ng $\times \mathrm{g}^{-1}$ d.w.). Summarizing, the Euonymus europaeus species (European spindle) is the best of the tested plants for the uptake of the target phthalates. The different sums of the uptake of PAEs are related to the morphological structures of the tested plants. E. europaeus and C. papyrus have a well-developed system of roots and rhizomes, thus, effectively delivering nutrients to the green parts of the plant. In addition, they show strong growth during the growing season, of up to $3 \mathrm{~m}$. L. nemorum is an evergreen creeping perennial herbaceous plant, growing to approximately $40 \mathrm{~cm}$, with a poorly developed rhizome system but an extensive root. The determination of PAEs in influent and effluent wastewater and in plant tissues allowed for the determination of which hydroponic cultivation system most significantly supported the wastewater treatment process (Tables 4-6).

\section{Materials and Methods}

\subsection{Chemicals and Materials}

EPA Method 8091A Phthalate Ester Mixtures containing the target compounds dimethyl phthalate (DMP), diethyl phthalate (DEP), di- $n$-butyl phthalate (DBP), benzyl butyl phthalate (BBP), di- $n$-octyl phthalate (DOP) and bis(2-ethylhexyl) phthalate (DEHP), ( $>99 \%)$ in hexane:acetone $(8: 2, v / v)$ at concentrations of $0.1 \mathrm{mg} \times \mathrm{L}^{-1}$ were obtained from Restek (Belle- 
fonte, PA, USA). High-purity analytical grade trace solvents methanol, dichloromethane and acetonitrile were supplied by $\mathrm{POCH}$ (Gliwice, Poland); ethyl acetate and acetone were purchased from Merck (Sigma Aldrich, Darmstadt, Germany). For the acidification of extracts, $37 \%$ hydrochloric acid $(\mathrm{HCl})$ was provided by Chempur (Piekary Ślaskie, Poland). Anhydrous magnesium sulfate was purchased from Eurochem BGD Sp. z o.o. (Tarnów, Poland). Solid-phase extraction (SPE) procedures were optimized using testing cartridges such as Oasis HLB (6 mL, $200 \mathrm{mg}$, Waters Corporation, Milford, MA USA), StrataX (3 mL, 200 mg, Phenomenex, Aschaffenburg, Germany) and Strata C18-ec (6 mL, $500 \mathrm{mg}$, Chromabond, Macherey-Nagel, Düren, Germany). Standard stock solutions of the target compounds $\left(10 \mu \mathrm{g} \times \mathrm{mL}^{-1}\right)$ were prepared in acetone. All the stock solutions were stored at $-20^{\circ} \mathrm{C}$. Working calibration standard solutions were prepared by diluting the standard stock solutions in the appropriate amounts of acetone, and they were stored in the dark at $-20^{\circ} \mathrm{C}$.

The chemical structures and physicochemical properties of the target PAEs in this study are presented in Table S3 in the Supplementary Materials.

\subsection{Characterization of the Studied Full-Scale MWWTP with CWs}

The investigations were performed at the full-scale municipal wastewater treatment plant (MWWTP) in Sochaczew (Mazowieckie Voivodeship, central Poland), which combines the method of biological wastewater treatment with AS and CWs (Figure S2 in the Supplementary Materials). This MWWTP was fully described in our previous paper [41]. Briefly, it is designed for a 55,925-equivalent population with a maximum daily volume of sewage at $11,636 \mathrm{~m}^{3} \times \mathrm{d}^{-1}$. The wastewater collection from the area of Sochaczew city concerns the domestic inflow from approximately 37,000 residents. The MWWTP consists of the following elements: $\left(1^{\circ}\right)$ the mechanical part of wastewater treatment including a drainage station, mechanical wastewater treatment using gratings and aerated sandboxes with degreasers (grates with a throughput of $515 \mathrm{~m}^{3} \times \mathrm{h}^{-1}$, aerated sand traps with degreasers, aerated at $\left.1.91 \mathrm{~m}^{3} \times \mathrm{min}^{-1}\right) ;\left(2^{\circ}\right)$ the biological part of wastewater treatment containing a flow reactor with AS with CWs and a secondary settler with recirculated sludge (flow reactor with AS with a throughput of $6000 \mathrm{~m}^{3} \times \mathrm{d}^{-1}$ and a secondary settling tank with an active capacity of $\left.1142 \mathrm{~m}^{3}\right) ;\left(3^{\circ}\right)$ a dehydration and liming sludge station. CWs are introduced at the stage of biological wastewater treatment $\left(2^{\circ}\right)$; contact between the plants and wastewater (mixed with AS) occurs only in the rhyzophytic zone (Figure S2 in the Supplementary Materials). CW plants are placed in a greenhouse with a total area of $1835.6 \mathrm{~m}^{2}$, where the optimal air humidity and temperature $\left(35-38^{\circ} \mathrm{C}\right)$ are maintained for appropriate plant growth (Figure S2). The effluent from the MWWTP is discharged into the Utrata River. The average values of the main MWWTP technological parameters are presented in Table S4 in the Supplementary Materials.

\subsection{Sampling Wastewater and Plant Materials from $\mathrm{CWs}$}

Both types of wastewaters (raw and treated) were collected in November 2017, in amber glass bottles $(2.5 \mathrm{~L})$, appropriately primed for the analysis of phthalates. Before taking the samples, all bottles were flushed with double-distilled water, then with high purity acetone free of the tested PAE residues. Influent was collected before mechanical treatment, and effluent wastewater was collected at the outlet to the Utrata River near the MWWTP. After delivery to the laboratory, all samples were filtered under pressure using a $1.2 \mu \mathrm{m}$ glass filter (washed in acetone) and, subsequently, frozen at $-20^{\circ} \mathrm{C}$ until analysis.

The three species of plants, Cyperus papyrus, Lysimachia nemorum and Euonymus europaeus, were also collected from the MWWTP; only the green part was taken to confirm the uptake of PAEs by plants in CWs. The plants were double-washed and dried in the laboratory for 3 days (temperature $\geq 23^{\circ} \mathrm{C}$ ). After that, the samples were dried at $60^{\circ} \mathrm{C}$ for $3 \mathrm{~h}$ in a heating oven (Pol-Eko Aparatura, Wodzisław Ślaski, Poland). The dried plants were homogenized using a mechanical blender (Kenwood, Havant, UK) and frozen at $-20{ }^{\circ} \mathrm{C}$ until analysis. The average water content in Cyperus papyrus, Lysimachia nemorum 
and Euonymus europaeus, determined based on the weight of the sample before and after desiccation, was $75.4 \%, 64.7 \%$ and $68.5 \%$, respectively.

\subsection{Development of the Analytical Method for Determining Target Compounds in Wastewater Samples}

Solid-phase extraction (SPE) was used for the extraction of phthalates from wastewater samples. In order to optimize the extraction conditions, three different cartridges, Oasis HLB, $6 \mathrm{~mL} / 300 \mathrm{mg}$, StrataX, $3 \mathrm{~mL} / 200 \mathrm{mg}$ and Strata C18-ec, $6 \mathrm{~mL} / 500 \mathrm{mg}$, were tested. Each cartridge was preconditioned with $5 \mathrm{~mL}$ of ethyl acetate (EtOAc), $5 \mathrm{~mL}$ of methanol $(\mathrm{MeOH})$ and $5 \mathrm{~mL}$ of distilled water adjusted to $\mathrm{pH} 3$ (using $1 \mathrm{M} \mathrm{HCl}$ ). Next, the spiked distilled water samples, with each analyte at a concentration of $4 \mu \mathrm{g} \times \mathrm{L}^{-1}(250 \mathrm{~mL}$ adjusted to $\mathrm{pH} 3$ ), were passed through a cartridge at a flow rate of $\sim 4.5 \mathrm{~mL} \times \mathrm{min}^{-1}$ using a vacuum manifold. After the sample was loaded, the sorbent was washed with $10 \mathrm{~mL}$ of a mixture of $\mathrm{MeOH}: \mathrm{H}_{2} \mathrm{O}(1: 9, v / v)$ and subsequently air-dried under a vacuum for $60 \mathrm{~min}$. The adsorbed analytes were eluted with $2 \times 5 \mathrm{~mL}$ of EtOAc and evaporated to dryness. Finally, the samples were reconstituted in $0.1 \mathrm{~mL}$ of acetone and analyzed by the GC-MS(SIM) method described in detail in Section 3.6. The extraction of non-spiked samples was carried out for each experiment.

In order to evaluate the usefulness of the analytical method for determining target compounds in wastewater samples, raw and treated sewage samples containing trace levels of PAEs were spiked with a known amount of the target phthalates $\left(250 \mathrm{ng} \times \mathrm{L}^{-1}\right.$, $500 \mathrm{ng} \times \mathrm{L}^{-1}$ and $1000 \mathrm{ng} \times \mathrm{L}^{-1}$ ) and subjected to extraction $24 \mathrm{~h}$ after spiking (each sample in three replicates). The extraction of non-spiked samples was also carried out for each experiment. The absolute recovery (AR) of analytes from both types of matrices was evaluated according to the procedure described in Caban et al. [42] using Equation (1):

$$
\mathrm{AR}=((\mathrm{C}-\mathrm{D}) / \mathrm{A}) \times 100 \%
$$

where $\mathrm{A}$ is the peak area of the analyte recorded for the standard solution, $\mathrm{C}$ is the peak area of the analyte recorded for the sample spiked with the target compound before extraction and $\mathrm{D}$ is the peak area of the analyte recorded for the non-spiked sample (blank sample). $\mathrm{AR}$ was presented as a mean value.

\subsection{Development of the Analytical Method for Determining Target Compounds in Plant Materials}

Ultrasound-assisted extraction (UAE) combined with SPE for cleaning the plant extracts was used for the extraction of phthalates from plant materials. The UAE extraction was performed using an SB 4200 DTD ultrasonic bath with temperature and power control systems (Polsonic, Warsaw, Poland). One gram of non-spiked dry papyrus (C. papyrus) material was put into a beaker, as well as material spiked with each analyte at a concentration of $1000 \mathrm{ng} \times \mathrm{g}^{-1}$ dry weight $(1 \pm 0.01 \mathrm{~g}$ d.w.) (each sample was prepared in three replicates), together with $20 \mathrm{~mL}$ of one of the solvents ethyl acetate (EtOAc), methanol $(\mathrm{MeOH})$ and dichloromethane (DCM), tested as the extraction medium. Such prepared samples were extracted under the following conditions: extraction time $30 \mathrm{~min}$, operating frequency $40,000 \mathrm{~Hz}$, temperature $25^{\circ} \mathrm{C}$. After this, the extracts were separated from the plant materials and decanted through a filter filled with $1 \pm 0.01 \mathrm{~g}$ of sodium sulfate. The samples were evaporated to dryness and dissolved in $10 \mathrm{~mL}$ of acetone. Next, water to a volume of $250 \mathrm{~mL}$ was added to each extract, and the obtained solution was subjected to a cleaning procedure using the SPE procedure described in Section 3.4 (Oasis HLB cartridge). Finally, the samples were reconstituted in $0.1 \mathrm{~mL}$ of acetone and analyzed by the GC-MS(SIM) method described in detail in Section 3.6. The extraction of the non-spiked sample was also carried out. For appropriate equilibration, the spiked plant samples were extracted after $24 \mathrm{~h}$ of their storage under controlled temperature in the darkness.

The AR and ME values of analytes from plant materials were calculated as described in Caban et al. [42]. 


\subsection{Chromatographic Conditions of GC-MS Measurements}

The plant and wastewater extracts were analyzed using the GCMS-QP 2010 SE Shimadzu System (Shimadzu, Kyoto, Japan) with an AOC-5000 autosampler. The carrier gas was helium (100 kPa). The separation of analytes was carried out using a Zebron ZB-5MSi fused-silica capillary column ( $30 \mathrm{~m}, 0.25 \mathrm{~mm}$ I.D., $0.25 \mu \mathrm{m}$ film thickness, Phenomenex). Injections $(1 \mu \mathrm{L})$ were performed in the splitless injector mode $(60-\mathrm{s})$. The temperature of the injector was $280^{\circ} \mathrm{C}$. The oven temperature program was $50^{\circ} \mathrm{C}$ for $1 \mathrm{~min}$, from $50^{\circ} \mathrm{C}$ to $310^{\circ} \mathrm{C}$ at $10^{\circ} \mathrm{C} \times \min ^{-1}$, and finally, $5 \mathrm{~min}$ at $310^{\circ} \mathrm{C}$ (total time of analysis $32 \mathrm{~min}$ ). The transfer line was held at $280^{\circ} \mathrm{C}$. The MS analysis (electron impact ionization $70 \mathrm{eV}$, temperature of the ion source $200^{\circ} \mathrm{C}$ ) was carried out using the single ion monitoring (SIM) mode. The scan time was $0.3 \mathrm{~s}$. The time windows were $12.95-14.35 \mathrm{~min}, 14.35-15.73 \mathrm{~min}$, 18.63-21.34 $\mathrm{min}, 21.34-24.02 \mathrm{~min}, 24.02-25.54 \mathrm{~min}$ and 25.54-26.77 $\mathrm{min}$. The parameters used for identifying analytes were retention time, quantitative ions and confirmation ions, shown in Table 7.

Table 7. Retention parameters (time allowed change $\pm 0.15 \mathrm{~min}$ ), time windows and SIM ions for the target compounds (quantitative and confirmation ions; quantitative ions are marked in bold).

\begin{tabular}{|c|c|c|c|c|}
\hline Number & Phthalates & $\begin{array}{l}\text { Retention Time } \\
\text { (Rt) [min] }\end{array}$ & $\begin{array}{c}\text { Characteristic Ions }(\mathrm{m} / \mathrm{z}) \\
\text { (Quantitative and } \\
\text { Confirmation Ions) }\end{array}$ & $\begin{array}{c}\text { Time Windows } \\
\text { [min] }\end{array}$ \\
\hline 1 & DMP & 13.250 & $163 ; 135 ; 164$ & 12.95-14.35 \\
\hline 2 & DEP & 15.060 & $149 ; 150 ; 177$ & $14.35-15.73$ \\
\hline 3 & DBP & 19.225 & $149 ; 205 ; 223$ & $18.63-21.34$ \\
\hline 4 & $\mathrm{BBP}$ & 23.015 & $149 ; 123 ; 206$ & 21.34-24.02 \\
\hline 5 & DOP & 24.575 & $149 ; 150 ; 279$ & $24.02-25.54$ \\
\hline 6 & DEHP & 26.035 & $149 ; 167 ; 261$ & $25.54-26.77$ \\
\hline
\end{tabular}

3.7. Validation of the Proposed Methods for Determining Target Compounds in wastewater and Plant Samples

The proposed methods were validated using working calibration standard solutions and matrix-matched calibration solutions according to the guidelines of the International Vocabulary of Metrology [40].

The matrix-matched calibration solutions for determining target PAEs in treated and untreated wastewater were prepared by spiking samples with eight different concentrations of the target PAEs ranging from 7.8 to $1000 \mathrm{ng} \times \mathrm{L}^{-1}$.

The matrix-matched calibration solutions for determining target PAEs in plant tissues were prepared by spiking plant samples with eight different concentrations of the target PAEs ranging from 19.5 to $2500 \mathrm{ng} \times \mathrm{g}^{-1} \mathrm{~d}$.w.

For each concentration level, three samples were prepared. Non-spiked samples were also analyzed.

The validation parameters linearity, correlation coefficient $\left(R^{2}\right)$, intermediate precision measurement (expressed by RSD, $n=3$ ), mean recovery $(\mathrm{MR})$, method detection limit (MDL) and method quantification limit (MQL) were established according to the procedures and calculations fully described in our previous papers [41,42].

The matrix effect (ME) was determined by spiking the appropriate amount of influent and effluent wastewater $(250 \mathrm{~mL})$ at concentrations of 250, 500 and $1000 \mathrm{ng} \times \mathrm{L}^{-1}$ of each target compound, following the SPE procedure, and they were analyzed (in three replicates) according to the proposed GC-MS method. The extraction of each non-spiked water sample was also carried out. The same procedure was applied for the determination of the ME parameter for the plant materials $\left(625,1250\right.$ and $2500 \mathrm{ng} \times \mathrm{g}^{-1} \mathrm{~d}$.w). ME values were calculated according to the paper by Caban et al. [42] and presented as a mean value. 


\subsection{Application of the Proposed Methods for the Determination of Target Compounds in} Wastewater and Plants Collected from an MWWTP

The previously developed and validated SPE-GC-MS(SIM) method for the determination of phthalates in wastewater samples was used to assess the number of target compounds in untreated and treated wastewater in an MWWTP. Wastewater samples (each in three replicates) were extracted and analyzed three times.

Among the plant species used in the MWWTP, three species were selected to assess the uptake of phthalates: papyrus (C. papyrus), European spindle (E. europaeus), yellow pimpernel (L. nemorum). The determination of the target compounds in plant materials was performed using the UAE-SPE-GC-MS(SIM) method proposed in this study. As with the wastewater samples, the plant samples (each in three replicates) were extracted and analyzed three times.

\subsection{Evaluation of the Effectiveness of Removing Phthalic acid Esters in an MWWTP}

The elimination efficiency (EE\%) of target PAEs from the wastewater stream in an MWWTP supported by CWs was established according to the procedure described in our previous paper [41] based on concentrations of phthalates in treated $\left(\mathrm{C}_{\text {treated }}\right)$ and untreated $\left(C_{\text {untreated }}\right)$ sewage (Equation (2)):

$$
\mathrm{EE} \%=\left(\mathrm{C}_{\text {untreated }}-\mathrm{C}_{\text {treated }}\right) /\left(\mathrm{C}_{\text {untreated }}\right) \times 100 \%
$$

This parameter enables the effectiveness of removing target PAEs in the studied MWWTP to be described.

\section{Conclusions}

In this study, the analysis of the possibility of using hydroponic cultivation for the removal of six phthalates: dimethyl phthalate (DMP), diethyl phthalate (DEP), di$n$-butyl phthalate (DBP), benzyl butyl phthalate (BBP), di-n-octyl phthalate (DOP) and bis(2-ethylhexyl) phthalate (DEHP), in a working full-scale MWWTP is presented. Three new plants, Cyperus papyrus (papyrus), Lysimachia nemorum (yellow pimpernel) and Euonymus europaeus (European spindle), were investigated for this purpose. For the first time, the uptake of PAEs by plants in a working full-scale MWWTP, which combines the method of biological wastewater treatment with AS and CWs, was determined.

The established elimination efficiency (EE) of the target compounds from wastewater ranged from $0 \%$ (DOP) to $98 \%$ (DEP). The EE value for DMP was not determined due to its concentration in wastewater below the MDL values. Among the three tested plant species, four of the six target PAEs were determined in C. papyrus (papyrus), and five in L. nemorum (yellow pimpernel) and E. europaeus (European spindle). Considering the sum of the uptake of the target PAEs by the plants, the highest uptake of phthalates was determined for E. europaeus (8938 $\mathrm{ng} \times \mathrm{g}^{-1}$ dry weight), thus, this plant was found to be optimal for supporting conventional MWWTPs. In summary, the application of the MWWTP-CW system allows for a significant increase in the removal of DEP, DBP, BBP and DEHP from the wastewater stream.

Supplementary Materials: The following are available online: Table S1. Literature data concerning on the studies of usefulness of hydroponically cultivated plants for removing target phthalic acid esters (PAEs) from sewage stream, Table S2. Literature data concerning on the determination of selected PAEs in plant materials, Table S3. Chemical structures and physicochemical properties of selected phthalic acid esters (phthalates), Table S4. Main technological parameters of the studied MWWTP (average values from 2017), Figure S1. Mass spectra of target compounds with the MS fragments assignation, Figure S2. Activated sludge chamber with a system of constructed wetlands in the investi-gated Municipal Wastewater Treatment Plant in Sochaczew (Mazowieckie Voi-vodeship, Poland), Figure S3. Examples of total ion chromatograms (TICs) recorded for raw (A) and treated (B) wastewater samples, Figure S4. Example chromatogram with marked SIM ions for determined target compounds in real Papyrus (Cyperus papyrus) samples, Figure S5. Example chromatogram with 
marked SIM ions for determined target compounds in real Yellow pimpernel (Lysimachia nemorum) samples, Figure S6. Example chromatogram with marked SIM ions for determined target compounds in real European spindle (Euonymus europaeus) samples.

Author Contributions: Conceptualization, D.W., J.K., F.Q.; Formal analysis, D.W.; Funding acquisition, D.W. and P.S.; Methodology, D.W. and B.T.; Project administration, J.K.; Resources, D.W.; Supervision, J.K.; Validation, D.W.; Writing—original draft, D.W.; Writing—review and editing, D.W. and J.K. All authors have read and agreed to the published version of the manuscript.

Funding: This research was funded by the Ministry of Science and Higher Education under grant nos. 539-T010-B455-20 and DS 531-T010-D593-21.

Institutional Review Board Statement: Not applicable.

Informed Consent Statement: Not applicable.

Data Availability Statement: Not applicable.

Acknowledgments: The authors are also grateful to the Municipal Wastewater Treatment Plant (MWWTP) in Sochaczew (Mazowieckie Voivodeship, Poland) for the very fruitful cooperation and the opportunity to obtain the required samples.

Conflicts of Interest: The authors declare no conflict of interest.

Sample Availability: Not applicable.

\section{References}

1. Gao, D.W.; Wen, Z.D. Phthalate Esters in the Environment: A Critical Review of Their Occurrence, Biodegradation, and Removal during Wastewater Treatment Processes. Sci. Total Environ. 2016, 541, 986-1001. [CrossRef] [PubMed]

2. Gao, M.; Dong, Y.; Zhang, Z.; Song, Z. Metabolism and Distribution of Dibutyl Phthalate in Wheat Grown on Different Soil Types. Chemosphere 2019, 236, 124293. [CrossRef] [PubMed]

3. Gómez-Hens, A.; Aguilar-Caballos, M.P. Social and Economic Interest in the Control of Phthalic Acid Esters. TrAC Trends Anal. Chem. 2003, 22, 847-857. [CrossRef]

4. Net, S.; Sempéré, R.; Delmont, A.; Paluselli, A.; Ouddane, B. Occurrence, Fate, Behavior and Ecotoxicological State of Phthalates in Different Environmental Matrices. Environ. Sci. Technol. 2015, 49, 4019-4035. [CrossRef]

5. Ahmad, S.; Khan, M.F.; Parvez, S.; Akhtar, M.; Raisuddin, S. Molecular Docking Reveals the Potential of Phthalate Esters to Inhibit the Enzymes of the Glucocorticoid Biosynthesis Pathway. J. Appl. Toxicol. 2017, 37, 265-277. [CrossRef]

6. Sicińska, P. Di- $n$-Butyl Phthalate, Butylbenzyl Phthalate and Their Metabolites Induce Haemolysis and Eryptosis in Human Erythrocytes. Chemosphere 2018, 203, 44-53. [CrossRef]

7. European Commission Commission Regulation 2018/2005 of 17 December 2018 Amending Annex XVII to Regulation (EC) No 1907/2006 of the European Parliament and of the Council Concerning the Registration, Evaluation, Authorisation and Restriction of Chemicals (REACH) as Regards Bi; 2018; Volume 6, pp. L 322/14-L 322/19. Available online: https:/ /op.europa.eu/en/ publication-detail/- / publication/f1630f96-029e-11e9-adde-01aa75ed71a1/language-en (accessed on 7 June 2021).

8. Net, S.; Delmont, A.; Sempéré, R.; Paluselli, A.; Ouddane, B. Reliable Quantification of Phthalates in Environmental Matrices (Air, Water, Sludge, Sediment and Soil): A Review. Sci. Total Environ. 2015, 515-516, 162-180. [CrossRef]

9. Lubecki, L.; Kowalewska, G. Plastic-Derived Contaminants in Sediments from the Coastal Zone of the Southern Baltic Sea. Mar. Pollut. Bull. 2019, 146, 255-262. [CrossRef]

10. Gorito, A.M.; Ribeiro, A.R.; Almeida, C.M.R.; Silva, A.M.T. A Review on the Application of Constructed Wetlands for the Removal of Priority Substances and Contaminants of Emerging Concern Listed in Recently Launched EU Legislation. Environ. Pollut. 2017, 227, 428-443. [CrossRef]

11. Chen, H.; Mao, W.; Shen, Y.; Feng, W.; Mao, G.; Zhao, T.; Yang, L.; Yang, L.; Meng, C.; Li, Y.; et al. Distribution, Source, and Environmental Risk Assessment of Phthalate Esters (PAEs) in Water, Suspended Particulate Matter, and Sediment of a Typical Yangtze River Delta City, China. Environ. Sci. Pollut. Res. 2019, 26, 24609-24619. [CrossRef]

12. Simoneit, B.R.T.; Medeiros, P.M.; Didyk, B.M. Combustion Products of Plastics as Indicators for Refuse Burning in the Atmosphere. Environ. Sci. Technol. 2005, 39, 6961-6970. [CrossRef]

13. Li, L.; Li, Y.; Biswas, D.K.; Nian, Y.; Jiang, G. Potential of Constructed Wetlands in Treating the Eutrophic Water: Evidence from Taihu Lake of China. Bioresour. Technol. 2008, 99, 1656-1663. [CrossRef]

14. Verlicchi, P.; Zambello, E. How Efficient Are Constructed Wetlands in Removing Pharmaceuticals from Untreated and Treated Urban Wastewaters? A Review. Sci. Total. Environ. 2014, 470-471, 1281-1306. [CrossRef]

15. Sim, C.H.; Yusoff, M.K.; Shutes, B.; Ho, S.C.; Mansor, M. Nutrient Removal in a Pilot and Full Scale Constructed Wetland, Putrajaya City, Malaysia. J. Environ. Manag. 2008, 88, 307-317. [CrossRef]

16. Li, T.; Fan, Y.; Cun, D.; Song, X.; Dai, Y.; Wang, F.; Wu, C.; Liang, W. Treatment Performance and Microbial Response to Dibutyl Phthalate Contaminated Wastewater in Vertical Flow Constructed Wetland Mesocosms. Chemosphere 2020, 246, 125635. [CrossRef] 
17. Qi, X.; Li, T.; Wang, F.; Dai, Y.; Liang, W. Removal Efficiency and Enzymatic Mechanism of Dibutyl Phthalate (DBP) by Constructed Wetlands. Environ. Sci. Pollut. Res. 2018, 25, 23009-23017. [CrossRef]

18. Witthayaphirom, C.; Chiemchaisri, C.; Chiemchaisri, W. Optimization of Reactive Media for Removing Organic Micro-Pollutants in Constructed Wetland Treating Municipal Landfill Leachate. Environ. Sci. Pollut. Res. 2020, 27, 24627-24638. [CrossRef]

19. Kotowska, U.; Karpinska, J.; Kapelewska, J.; Kowejsza, E.M.; Piotrowska-Niczyporuk, A.; Piekutin, J.; Kotowski, A. Removal of Phthalates and Other Contaminants from Municipal Wastewater during Cultivation of Wolffia Arrhiza. Process. Saf. Environ. Prot. 2018, 120, 268-277. [CrossRef]

20. Xiaoyan, T.; Suyu, W.; Yang, Y.; Ran, T.; Yunv, D.; Dan, A.; Li, L. Removal of Six Phthalic Acid Esters (PAEs) from Domestic Sewage by Constructed Wetlands. Chem. Eng. J. 2015, 275, 198-205. [CrossRef]

21. Zavoda, J.; Cutright, T.; Szpak, J.; Fallon, E. Uptake, Selectivity, and Inhibition of Hydroponic Treatment of Contaminants. J. Environ. Eng. 2001, 127, 502-508. [CrossRef]

22. Reyes-Contreras, C.; Matamoros, V.; Ruiz, I.; Soto, M.; Bayona, J.M. Evaluation of PPCPs Removal in a Combined Anaerobic Digester-Constructed Wetland Pilot Plant Treating Urban Wastewater. Chemosphere 2011, 84, 1200-1207. [CrossRef]

23. Liang, W.; Deng, J.; Zhan, F.; Wu, Z. Effects of Constructed Wetland System on the Removal of Dibutyl Phthalate (DBP). Microbiol. Res. 2009, 164, 206-211. [CrossRef]

24. Masi, F.; Conte, G.; Lepri, L.; Martellini, T.; del Bubba, M.; Florence, I. Endocrine Disrupting Chemicals (EDCs) and Pathogens Removal in an Hybrid CW System for a Tourist Facility Wastewater Treatment and Reuse. Proc. 9th IWA Int. Conf. Wetl. Syst. Water Pollut. Control. 2004, 2, 461-468.

25. Zhao, W.Y.; Wu, Z.B.; Zhou, Q.H.; Cheng, S.P.; Fu, G.P.; He, F. Removal of Dibutyl Phthalate by a Staged, Vertical-Flow Constructed Wetland. Wetlands 2004, 24, 202-206. [CrossRef]

26. Xu, S.; Zhou, S.; Xing, L.; Shi, P.; Shi, W.; Zhou, Q.; Pan, Y.; Song, M.-Y.; Li, A. Fate of Organic Micropollutants and Their Biological Effects in a Drinking Water Source Treated by a Field-Scale Constructed Wetland. Sci. Total Environ. 2019, 682, 756-764. [CrossRef]

27. Diepenheim, G.; Gift, S.C.; Harb, C.; Wallace, M.; Layshock, J. Survey of Phthalate Mitigation and Distribution in Water, Sediment, and Typha in a Fully Operational Constructed Wetland: A Pilot Study. Bull. Environ. Contam. Toxicol. 2020, 105, 205-210. [CrossRef]

28. Zhou, Q.H.; Wu, Z.B.; Cheng, S.P.; He, F.; Fu, G.P. Enzymatic Activities in Constructed Wetlands and Di- $n$-Butyl Phthalate (DBP) Biodegradation. Soil Biol. Biochem. 2005, 37, 1454-1459. [CrossRef]

29. Liao, C.-S.; Nishikawa, Y.; Shih, Y.-T. Characterization of Di- $n$-Butyl Phthalate Phytoremediation by Garden Lettuce (Lactuca Sativa L. Var. Longifolia) through Kinetics and Proteome Analysis. Sustainability 2019, 11, 1625. [CrossRef]

30. Fu, X.; Du, Q. Uptake of Di-(2-Ethylhexyl) Phthalate of Vegetables from Plastic Film Greenhouses. J. Agric. Food Chem. 2011, 59, 11585-11588. [CrossRef] [PubMed]

31. Gao, M.; Dong, Y.; Zhang, Z.; Song, W.; Qi, Y. Growth and Antioxidant Defense Responses of Wheat Seedlings to Di- $n$-Butyl Phthalate and Di-(2-Ethylhexyl) Phthalate Stress. Chemosphere 2017, 172, 418-428. [CrossRef] [PubMed]

32. Ma, T.T.; Christie, P.; Luo, Y.M.; Teng, Y. Phthalate Esters Contamination in Soil and Plants on Agricultural Land near an Electronic Waste Recycling Site. Environ. Geochem. Health 2013, 35, 465-476. [CrossRef] [PubMed]

33. Sun, J.; Wu, X.; Gan, J. Uptake and Metabolism of Phthalate Esters by Edible Plants. Environ. Sci. Technol. 2015, 49, 8471-8478. [CrossRef] [PubMed]

34. Jiang, J.; Mu, D.; Ding, M.; Zhang, S.; Zhang, H.; Hu, J. Simultaneous Determination of Primary and Secondary Phthalate Monoesters in the Taihu Lake: Exploration of Sources. Chemosphere 2018, 202, 17-24. [CrossRef] [PubMed]

35. Ballesteros, O.; Zafra, A.; Navalón, A.; Vílchez, J.L. Sensitive Gas Chromatographic-Mass Spectrometric Method for the Determination of Phthalate Esters, Alkylphenols, Bisphenol A and Their Chlorinated Derivatives in Wastewater Samples. J. Chromatogr. A 2006, 1121, 154-162. [CrossRef]

36. Adewuyi, G.O. High Performance Liquid Chromatographic Identification and Estimation of Phthalates in Sewer Waste and a Receiving River in Ibadan City, Southwestern Nigeria. J. Water Resour. Prot. 2012, 04, 851-858. [CrossRef]

37. Borecka, M.; Białk-Bielińska, A.; Siedlewicz, G.; Kornowska, K.; Kumirska, J.; Stepnowski, P.; Pazdro, K. A New Approach for the Estimation of Expanded Uncertainty of Results of an Analytical Method Developed for Determining Antibiotics in Seawater Using Solid-Phase Extraction Disks and Liquid Chromatography Coupled with Tandem Mass Spectrometry Technique. J. Chromatogr. A 2013, 1304, 138-146. [CrossRef]

38. Sablayrolles, C.; Montréjaud-Vignoles, M.; Benanou, D.; Patria, L.; Treilhou, M. Development and Validation of Methods for the Trace Determination of Phthalates in Sludge and Vegetables. J. Chromatogr. A 2005, 1072, 233-242. [CrossRef]

39. Holadová, K.; Hajšlová, J. A Comparison of Different Ways of Sample Preparation for the Determination of Phthalic Acid Esters in Water and Plant Matrices. Int. J. Environ. Anal. Chem. 1995, 59, 43-57. [CrossRef]

40. de Bièvre, P. The 2012 International Vocabulary of Metrology: "VIM". Accredit. Qual. Assur. 2012, 17, 231-232. [CrossRef]

41. Wolecki, D.; Caban, M.; Pazda, M.; Stepnowski, P.; Kumirska, J. Evaluation of the Possibility of Using Hydroponic Cultivations for the Removal of Pharmaceuticals and Endocrine Disrupting Compounds in Municipal Sewage Treatment Plants. Molecules 2020, 25, 162. [CrossRef]

42. Caban, M.; Migowska, N.; Stepnowski, P.; Kwiatkowski, M.; Kumirska, J. Matrix Effects and Recovery Calculations in Analyses of Pharmaceuticals Based on the Determination of $\beta$-Blockers and $\beta$-Agonists in Environmental Samples. J. Chromatogr. A 2012, 1258, 117-127. [CrossRef] 
43. Fernández-González, V.; Moscoso-Pérez, C.; Muniategui-Lorenzo, S.; López-Mahía, P.; Prada-Rodríguez, D. Reliable, Rapid and Simple Method for the Analysis of Phthalates in Sediments by Ultrasonic Solvent Extraction Followed by Head Space-Solid Phase Microextraction Gas Chromatography Mass Spectrometry Determination. Talanta 2017, 162, 648-653. [CrossRef]

44. Gao, D.; Li, Z.; Wen, Z.; Ren, N. Occurrence and fate of phthalate esters in full-scale domestic wastewater treatment plants and their impact on receiving waters along the Songhua River in China. Chemosphere 2014, 95, 24-32. [CrossRef]

45. Gani, K.M.; Kazmi, A.A. Evaluation of Three Full Scale Sewage Treatment Plants for Occurrence and Removal Efficacy of Priority Phthalates. J. Environ. Chem. Eng. 2016, 4, 2628-2636. [CrossRef] 